\title{
ENTRE MEMÓRIA E PROMESSA: A IDENTIDADE DE CIÊNCIA NA REVISTA GALILEU
}

\author{
Natália Flores \\ Ada Cristina Machado da Silveira ${ }^{* *}$
}

Resumo: Neste artigo, pretendeu-se analisar como se produz a identidade de ciência na revista Galileu. Partimos do pressuposto de que a midia é constitutiva das identidades, as quais não se referem apenas a um produto determinado, mas se constroem na confluência de diferentes elementos de acordo com a historicidade de suas formações discursivas. As nossas questões norteadoras indagam sobre a presença de elementos idem e ipse - da identidade narrativa em Paul Ricoeur (1991) -, e sua relação com as formações discursivas na constituição da identidade de ciência no discurso da revista. O corpus da pesquisa se constitui de quatro reportagens de capa da revista Galileu, das ediçoes de abril, maio, junho e julho de 2010. Analisa-se como a atividade da ciência numa concepção moderna ou pós-moderna colabora para a construção das identidades de ciência na Galileu e constitui a tensão entre mesmidade e ipseidade, entre memória e promessa.

Palavras-chave: Identidade. Formacõos discursivas. Revista Galileu

\section{INTRODUÇÃO}

O fenômeno da midiatização produziu um novo status para a mídia, tornando-a referência de valores, costumes e crenças para a sociedade. Nessa nova ambiência, a questão da identidade construída pelas instâncias midiáticas torna-se central, pois influi no modo como os sujeitos sociais entendem o mundo. Segundo Sodré (2002), os veículos de comunicação na sociedade midiatizada passam a modificar percepções e costumes da cultura tradicional e fazem com que o indivíduo experimente um novo tipo de relacionamento com referências concretas e suas realidades. Antes que consumir produtos, o indivíduo consome realidades construídas pela mídia.

\footnotetext{
* Bacharel em Jornalismo pela Universidade Federal de Santa Maria - UFSM. Mestranda do Programa de Pós-graduação em Comunicação - UFSM. Email: nataliflores@gmail.com.

** Bacharel em Jornalismo pela Universidade do Rio dos Sinos. Doutor em Periodismo pela Universitat Autonoma de Barcelona (2000), com estágio pós-doutoral na Sorbonne III (La Nouvelle). Professor associado II da Universidade Federal de Santa Maria e pesquisadora do CNPq. Professor do Programa de Pós-graduação em Comunicação da Universidade Federal de Santa Maria - UFSM. Email: ada.machado@pq.cnpq.br .
} 
Ao transformar-se em referência na construção da realidade social, a instância midiática, segundo analisa Sodré (2002), passou a servir de orientadora das condutas do homem contemporâneo, prescrevendo modos de ser e de agir corretos, por meio da oferta de realidades já estabelecidas. Giddens (2002) afirma que, muitas vezes, as realidades construídas por essa instância parecem ter existência mais concreta do que o objeto real, pois a mídia tem esse poder de inversão.

Nos seus estudos, Orlandi (1998) entende que as identidades se constituem por meio de processos linguísticos e discursivos. $\mathrm{Na}$ atualidade, elas encontram na mídia o seu agente constitutivo. A importância de estudar a construção dessas identidades midiáticas se dá devido à própria natureza ideológica que as constitui, por meio de jogos de linguagem. Como afirmam Gomes, Holzbach e Taveira (2003), são as identidades que definem o olhar do homem contemporâneo sobre a realidade. Assim, elas podem criar ou reforçar estereótipos acerca da ciência.

Nessa perspectiva, no presente artigo pretendeu-se entender como se produz a construção da identidade de ciência na revista Galileu, utilizando os conceitos de mesmidade (idem) e ipseidade (ipse) da teoria narrativa de Ricoeur (1991). A análise aprofundada de quatro reportagens centrais das edições de abril, maio, junho e julho de 2010 teve como questões norteadoras a presença dos elementos idem e ipse e a sua relação com as formações discursivas caudatárias de uma compreensão da modernidade e da pós-modernidade na constituição das identidades de ciência no discurso da revista. Partimos do pressuposto de que as identidades de ciência exposta em processos midiáticos se constituem de acordo com a historicidade de suas formações discursivas (SILVEIRA, 2007), numa relação entre língua e história (ORLANDI, 1998).

\section{REFERENCIAL TEÓRICO}

\subsection{A FRAGMENTAÇÃO DE IDENTIDADES}

Num contexto de pós-modernidade, em que há o posicionamento da cultura na esfera de mercadoria e de consumo, o processo de construção de identidades passou a ser evidenciado por diversos estudiosos. O fenômeno pós-industrial e a globalização criam novas 
identidades não mais relacionadas com as formas antigas de identificação presentes na modernidade. Nesse cenário, Kellner (2001) avalia que a cultura da mídia torna-se central no papel de desestabilizar identidades com a produção de outras identificações mais instáveis, fluidas e variáveis.

A pós-modernidade rompe com a noção tradicional de identidade construída na modernidade. Ao estudar as identidades pós-modernas, Hall (2005) afirma que o contexto pós-moderno modifica a identidade fixa e única da modernidade, fazendo com que surjam identidades múltiplas e fragmentadas. A identidade se transforma numa celebração móvel em constante transformação.

De acordo com Kellner (2001), a própria segmentação de mercado proporcionou a intensificação da construção e fragmentação de identidades. Por meio da comercialização de diversos produtos culturais, a mídia passou a oferecer uma enorme quantidade de posições de sujeitos para seus consumidores, os quais foram estruturando suas identidades individuais conforme as imagens produzidas pelos produtos.

A fluidez e a fragmentação das identidades pós-modernas permitem que pensemos a identidade de ciência da revista Galileu não como única e fixa, mas como uma construção que se ocupa de uma heterogeneidade de identidades ofertadas pelos percursos históricos que as constituíram. Assim, como analisa Silveira (2007), a identidade não é propriedade discursiva de apenas um produto, mas é explorada nas diferentes vozes de acordo com a historicidade de suas formações discursivas.

\subsection{A IDENTIDADE DA CIÊNCIA MODERNA}

A presença de marcas da historicidade discursiva da ciência na constituição das suas identidades midiáticas permite que adotemos a perspectiva de Orlandi (1998), que trata o processo de produção da identidade como uma relação entre língua e história. Para ela, a identidade é uma construção discursiva feita por meio de mecanismos de produção de sentido marcada por determinações históricas, um movimento na história. Assim também ocorre com a produção de identidades ou identificações de ciência, as quais foram construídas estrategicamente por meio de demarcações simbólicas dentro do discurso científico de acordo com a sua trajetória histórica. 
A atividade científica gerou, ao longo dos séculos, identificações distintas dos cientistas com seus paradigmas. Segundo Hall (2009), estas podem ser entendidas como pontos de apego temporário a posições-desujeito construídas pelas práticas discursivas. Produzidas em lugares históricos específicos (HALL, 2009), as identidades de ciência produziram, dentro do discurso científico, posições para a ciência e para o cientista.

As posições-de-sujeito construídas pelo paradigma científico moderno posicionaram a ciência em lugares relacionados à razão, à neutralidade e à precisão. De acordo com o pesquisador Japiassú (1982), a filiação à razão excluiu do campo epistemológico da atividade científica todas as valorações, interpretações e subjetividades do cientista, desumanizando-o ao colocá-lo numa posição de imparcialidade.

A partir da modernidade, a ciência adquiriu uma unidade identitária que a definia como verdade absoluta capaz de desvendar as verdades do mundo por meio de métodos matemáticos e físicos. Essa identidade moderna, caracterizada por Hall (2005) como fixa e unificada, foi construída por meio de processos de exclusão dos elementos tidos como não-científicos.

De acordo com Hall (2009), o contato com a diferença é essencial para a construção das identidades. Segundo ele, esse processo funciona por meio do enclausuramento de elementos tidos como integrados àquela identidade e exclusão dos outros. Assim, a unidade proclamada pela identidade da ciência foi construída social e historicamente por meio desses processos que traçaram limites entre o científico e o nãocientífico. Muitas vezes é a capacidade de excluir que faz com que a identidade ganhe força e sirva de ponto de identificação e apego ao longo da sua história (HALL, 2009).

Bauman (1996) se refere à identidade como uma invenção moderna. Segundo ele, esse é o nome dado para o escape da incerteza perante os outros e perante si mesmo. Assim, tanto a identidade atribuída à ciência como o processo de identificação dos cientistas em relação ao campo científico trazem marcas da procura de elementos de representação e distinção perante outras identificações (a não-ciência) na procura de uma certeza (a consolidação da ciência). 
O processo de produção da ciência moderna - e suas identidades e identificações -, como afirma Santos (2006), baseou-se na demarcação de fronteiras ostensivas entre atividade e os conhecimentos ditos irracionais, como o senso comum e as humanidades. O processo de demarcação ocorre de forma tão rigorosa que Santos (2006, p.21) caracteriza o paradigma da ciência moderna como totalitário, "na medida em que nega o caráter racional a todas as formas de conhecimento que se não pautarem pelos seus princípios epistemológicos e pelas suas regras metodológicas".

Apesar de a ciência moderna ser construída discursivamente como uma unidade fixa, durante os séculos seguintes, alguns elementos da sua identidade foram desestruturando-se, enquanto novos componentes se integraram a ela. Esse processo de mudança, de acordo com Hall (2009), é natural das identidades, sujeitas a uma historicização radical que as impede de serem estáticas.

\subsection{A EMERGÊNCIA DE UMA IDENTIDADE DE CIÊNCIA PÓS-MODERNA}

Ao estudar o processo de construção das identidades, Silva (2009) ressalta que a relação entre identidade e diferença nunca é estável. Como os elementos que os diferenciam são construídos por atos linguísticos, a identidade e a diferença são também marcadas pela indeterminação e pela instabilidade da linguagem. Assim, a identidade nunca é definitiva e nunca fecha em si mesma, pois ela sempre está em contato com o que ela não é.

$\mathrm{Na}$ pós-modernidade, o contato com a diferença proporciona modificações nas identificações de ciência. Lyotard (1988) estuda o mundo pós-moderno como um período de crise dos cânones modernistas, em que a incredulidade em relação aos grandes relatos se generaliza. Essa crise acaba por originar diversas narrativas que competem entre si. Nesse contexto de pluralidade, a ciência se deslegitima como grande relato diante de outros saberes. Lyotard (1988) entende que esta passa a ser entendida como jogo de linguagem capaz de inventar suas próprias regras e de conviver com outras narrativas independentes entre si no mundo fragmentado e disperso da pósmodernidade. Assim, ela joga seu próprio jogo e não tem mais o poder absoluto de legitimar ou interferir em outros jogos de linguagem. 
Segundo Santos (2006), na pós-modernidade a ciência passa por um processo de reavaliação em que alguns elementos constituintes da sua matriz moderna, como a verdade absoluta, não cabem mais para explicar a fase contemporânea. Nesse processo, os cientistas passaram a entender a atividade não mais como um conhecimento-estado e sim como um conhecimento-processo que se encontra em constante inacabamento (JAPIASSÚ, 1975).

O processo de identificação dos cientistas passa a atuar no reconhecimento de outros elementos diferentes da sua identidade moderna. De acordo com Santos (2006), começou-se a entender que, como construção humana, a ciência só poderia conseguir resultados aproximados e não exatos e deterministas como pretendia o paradigma moderno. O rigor matemático também perde seu valor e passa a ser entendido como apenas uma das formas de rigor construídas e que, por isso, estaria sujeita a critérios de seletividade e eventuais erros.

O universo científico passou a lidar com causas imprevisíveis e com objetos complexos, os quais possuíam fronteiras menos definidas. Nessa perspectiva, o conhecimento científico envolve-se numa profunda reflexão epistemológica rica e diversificada, que dá espaço a pluralidades e não mais à unidade científica moderna (SANTOS, 2006; 1989). Esse espaço plural de identificação do meio científico permite que a ciência adquira uma identidade fragmentada e múltipla, nomeada por Hall (2009) como pós-moderna. Assim, a fixidez e unificação dessa identidade, verdade absoluta na modernidade, desestabiliza-se com a pósmodernidade, tornando-se fragmentada, incerta.

Apesar de se constituir no discurso científico, as identidades e identificações de ciência não são produzidas apenas nesse contexto. $\mathrm{Na}$ atualidade, elas são construídas também pela instância midiática, pois a mídia passa a ser o agente constitutivo das identidades (SILVEIRA, 2007). Produzidas por meio do discurso jornalístico, essas identidades se articulam no movimento de unidade e dispersão do discurso, o que faz com que não existam identidades homogêneas e fixas. Ao contrário, a identidade de ciência na revista Galileu é constituída por diversos fragmentos. 


\subsection{A REVISTA GALILEUE A OFERTA DE RESPOSTAS CIENTÍFICAS}

A revista Galileu foi lançada em 1991 pela Editora Globo durante o momento de expansão do mercado editorial brasileiro de revistas. A sua proposta inicial, segundo Gomes, Holzbach e Taveira (2003) era cobrir assuntos de ciência e tecnologia que afetassem o dia-a-dia das pessoas. Atualmente, a revista é editada mensalmente e alcança uma tiragem de 160 mil exemplares por mês. Conforme Tucherman, Oiticica e Cavalcanti (2010a), a revista pretende antecipar tendências e interpretar a vida a partir dos conhecimentos de ciência para um público na faixa etária de 18 a 34 anos de ambos os sexos.

Assim como outras revistas, segundo analisa Mira (2001), o surgimento da Galileu não ocorreu devido apenas à lógica do mercado, mas também foi impulsionado por outras condições socioculturais existentes. Num contexto em que a modernidade traz ao homem a necessidade de se relacionar com conteúdos do mundo da ciência, as publicações de divulgação científica se erigem num ponto de segurança no qual o sujeito se firma frente ao mundo fragmentado e em constante transformação. Assim, antes de apoiar-se na esfera religiosa como acontecia nas sociedades pré-modernas, Giddens (1991) entende que o homem moderno vai depositar sua confiança em outros sistemas peritos, como a ciência. Esse período é, então, propício para o surgimento de publicações especializadas em traduzir o campo científico para as práticas do cotidiano, como a revista Galileu.

A necessidade de oferecer respostas úteis e transmitir segurança a esse homem contemporâneo molda os conteúdos da divulgação científica na mídia que oferecem ao leitor a ciência como solução de problemas no propósito de captá-lo para a leitura: "Trata-se de fazer crer ao leitor que ele está na presença de fatos incontestáveis, prevenir suas objeções, transmitir segurança, persuadindo-o do acesso a esse saber e até mesmo da sua necessidade" (Roqueplo apud CORACINI, 2003, p. 329).

A revista Galileu oferece realidades para seus leitores e, como produto cultural, prescreve implicitamente modos de agir e de pensar considerados modernos ou melhores para a inserção social do sujeito na contemporaneidade (SODRÉ, 2002). Na revista, são oferecidas 
orientações comprovadas pelo ponto de vista científico de como viver no mundo contemporâneo, apresentando assuntos como cultura, tecnologia e ciência.

O funcionamento da lógica de oferta de realidades, segundo Sodré (2002), se dá por meio de uma doutrina de acompanhamento, em que a mídia oferece realidades socialmente estabelecidas. Essa lógica de aplica à revista Galileu, quando esta utiliza, muitas vezes, a ciência como legitimadora dos assuntos tratados pela publicação (TUCHERMAN; OITICICA; CAVALCANTI, 2010b).

Ao tratar sobre a divulgação científica, Coracini (2003) comenta que a exposição da ciência na mídia não é mais a ciência do trabalho de pesquisa, mas são representações acerca da atividade construídas pela mídia. Muitas vezes, no entanto, essas representações midiáticas se convertem na realidade vivida do indivíduo (SODRÉ, 2002). Assim, as identidades construídas pela mídia ganham projeção maior.

\section{METODOLOGIA}

Neste artigo, analisamos como se produz a construção da identidade de ciência nas reportagens de capa de quatro edições da revista Galileu do ano de 2010, intituladas "O futuro da comida" (abril/2010), "O lado bom da depressão" (maio/2010), "A nova tropa de elite" (junho/2010) e "Uma cura para todos os medos?" (julho/2010). Escolheu-se delimitar a análise às reportagens de capa devido à importância que estas detêm na estruturação da publicação. A reportagem de capa é uma matéria assinada de, em média, 12 páginas que possui infográficos e fotos que ilustram o tema abordado.

A análise das reportagens orientou-se pelos conceitos de mesmidade e ipseidade da teoria da identidade narrativa, de Ricoeur (1991), e de formação discursiva, de Michel Foucault (1972). A relação entre esses dois conceitos, segundo entendemos, traz luz ao modo como a identidade de ciência se conforma na publicação, já que a identidade se constitui segundo processos linguísticos e discursivos (ORLANDI, 1998).

A teoria de identidade narrativa de Ricoeur (1991) propõe estudar a permanência no tempo da identidade por meio da identificação pela narrativa. Segundo essa teoria, a narrativa estabelece a conexão e unidade 
entre acontecimentos desiguais, por meio da mediação entre concordâncias, relacionadas à ordem, e discordâncias, relacionadas a mudanças de destino. A abordagem hermenêutica de Ricoeur estabelece uma distinção com a abordagem científica, ao enfatizar o momento da explicação - que lhe é próprio - e o momento da compreensão próprio da hermenêutica.

Nessa perspectiva, as identidades se constituiriam numa concordância discordante, representada pela dialética da mesmidade e da ipseidade, numa relação entre elementos idem e ipse. O primeiro denomina aspectos imutáveis que fixam a identidade no tempo, concernentes à tradição e à memória. Em oposição, os elementos ipse se referem aos componentes mutáveis da identidade, a qual pode adquirir uma multiplicidade de variações. Em outras palavras, a identidade é produzida segundo o que ela é e o que ela deseja tornar-se numa relação entre memória e promessa.

A aplicação desses conceitos no corpus ocorreu por meio do deslocamento da problemática filosófica dos elementos ipse e idem para uma temática midiática - a sua presença na revista Galileu. Para isso, optou-se por compreender como essa identidade narrativa transforma-se numa identidade discursiva, produzindo significados por meio do texto e dando forma à dialética da identidade narrativa. Essa proposição torna-se coerente quando analisamos a interpretação de Greimas e Courtés (2008), de que Genette opõe a narrativa ao discurso ao definir o primeiro como o que é narrado e o segundo como o modo se contar a narrativa.

O segundo conceito utilizado na análise das reportagens de Galileu é o de formação discursiva, que se refere ao sujeito da enunciação e seu poder como sujeito autorizado de dizer algo em determinado tempo e espaço. Segundo Foucault (1972), ela consiste num conjunto de regras históricas que determinam o ato de enunciação em determinada época. Nesse processo, constituído num modus operandi, o discurso jornalístico tem na interdiscursividade o seu poder de conectar e relacionar discursos pertencentes a diversas formações discursivas (PIPPI, 2005, p. 57).

$\mathrm{Na}$ constituição da identidade de ciência na revista Galileu, os elementos idem e ipse que constituem a identidade narrativa ganham formas discursivas de acordo com a maneira de contar e podem ser relacionados às formações discursivas da modernidade e da pósmodernidade, que perpassam o discurso sobre ciência na publicação. 


\section{RESULTADOS}

\subsection{ELEMENTO IDEM: FORMAÇÃO DISCURSIVA DA MODERNIDADE}

Os elementos idem, segundo Ricoeur (1991), vinculam-se à memória e à tradição e se relacionam à estrutura e à estabilidade da identidade. Na revista Galileu, os elementos idem da identidade da ciência se referem à formação discursiva da modernidade, posição de enunciação que assume a ciência como verdade absoluta, baseada no racionalismo e no progresso cientificista.

A formação discursiva da modernidade instituiu-se na época moderna, em que há a emergência da racionalidade da ciência. Como relata Floriani (2000), nesse período a ciência passa a ser vinculada ao desenvolvimento econômico, técnico e social dos Estados modernos e, assim, integra-se ao seu sistema social. O saber científico racional ganha valor supremo na sociedade como verdade absoluta devido ao pensamento progressista e otimista da época moderna. Japiassú (2000) relata que esse valor ainda está presente na cultura contemporânea, em que é quase automático relacionar a ciência ao progresso e ao desenvolvimento.

Os componentes de mesmidade presentes nas reportagens da Galileu vinculam a ciência ao seu passado moderno e progressista. Para Hall (2009), esse contato com o seu passado histórico é característico de algumas identidades, que invocam suas origens para se firmar. No exemplo 1, da matéria "O futuro da comida" da revista Galileu, pode-se observar o modo como a ciência é construída relacionada ao seu passado.

Exemplo 1: Foi ela [a ciência] que criou coisas revolucionárias, como a geladeira e o micro-ondas. Essas invenções nos fizeram gastar menos recursos e esforço para descobrir sensações e sabores (REVISTA Galileu, abril, 2010). 
A identidade fixa da ciência também aparece em trechos em que os fenômenos são explicados do ponto de vista científico. Essa abordagem legitima o campo científico, capaz de dar explicações racionais e aceitas universalmente, características relacionadas à ciência moderna. No corpus analisado, predominam as explicações do ponto de vista das ciências biológicas sobre o corpo e a mente humana.

De acordo com Japiassú (1982), o eixo biológico da ciência moderna converte o ser humano em uma regulação biológica interna que faz com que dados da superfície, como a cultura e a tradição, percam seu valor na determinação das ações do homem. Essa abordagem, segundo Silva e Oiticica (2009), é característica do projeto biopolítico contemporâneo, que transforma os aspectos psicológicos em biológicos, fazendo uma analogia entre homem e máquina. Essa característica aparece nos exemplos 2, 3, 4 e 5:

Exemplo 2: Alimentar-se, em seu significado primário, é apenas nutrir o corpo para que ele possa reproduzir-se. Então, ser saudável é comer em quantidade suficiente para ter filhos sem ficar doente no processo (REVISTA Galileu, abril, 2010).

Exemplo 3: Guiados pela teoria da seleção natural de Charles Darwin (1809-1882), o psiquiatra J. Anderson Thomson, da University of Virgínia, e o psicólogo Paul W. Andrews, da Virginia CommonWealth University, passaram anos tentando entender porque doenças mentais como a esquizofrenia afetam apenas $1 \%$ a $2 \%$ da população mundial, enquanto a depressão atinge mais de 20\% (REVISTA Galileu, maio 2010).

Exemplo 4: Trata-se de um afinadíssimo mecanismo de seleção e especialização que garante a permanência de traços que nos deixam mais aptos a encarar os obstáculos (REVISTA Galileu, maio 2010).

Exemplo 5: Formadas por proteínas, essas redes são responsáveis por manter a memória do medo ativa (REVISTA Galileu, julho 2010).

Segundo acredita Coracini (2003), no intuito de oferecer segurança diante de um mundo fragmentado e em constante transformação, as 
notícias sobre ciência representam a atividade propositadamente expressa como fonte de certeza absoluta. Nas matérias jornalísticas, entendemos que o elemento idem procura servir como ponto de segurança aos leitores a quem se dirige. Esse contexto vai ao encontro da proposição de Giddens (1991), de que, na modernidade, a ciência serve como segurança e referência ao homem moderno.

\subsection{ELEMENTO IPSE: PROMESSAS DE FUTURO E ABERTURA PARA UMA CIÊNCIA PÓS-MODERNA}

A identidade fixa e imutável da ciência relaciona-se com alguns elementos que permitem que ela seja flexível e mutável, os chamados elementos ipse. De acordo com Ricoeur (1991), a ipseidade é a capacidade de promessa de futuro, de mudança. Assim, nas matérias da revista Galileu, esse elemento relaciona-se, primeiramente, às promessas científicas oferecidas pela revista ao leitor. Num segundo momento, os elementos ipse mostram o surgimento de uma ciência com componentes diferentes da ciência moderna - uma possível abertura para a ciência pós-moderna conceituada por Santos (1989).

Em alguns trechos das reportagens de Galileu, notamos aspectos da identidade ipse que fornecem promessas ao leitor em que a ciência aparece como solução para os problemas abordados pelas reportagens. A relação com o futuro e com a tecnologia é evidente e identifica os elementos ipse dessa identidade com a formação discursiva da modernidade. A ciência progressista, instrumento técnico que visa principalmente atingir objetivos tecnológicos e tirar o máximo proveito da natureza, é própria da modernidade (FLORIANI, 2000) e ocorre nos exemplos 6 e 7 .

Exemplo 6: O físico-químico francês Hervé This, um dos idealizadores da gastronomia molecular (corrente do fim dos anos 80 que trouxe a ciência para a cozinha) pensou na 'cozinha nota a nota' para liquidar a questão. Para ele, essas notas são o futuro (REVISTA Galileu, abr. 2010).

Exemplo 7: Com os novos equipamentos, é possível reprocessar evidências e finalmente colocar na prisão os culpados. Prova de que a tecnologia pode ser mais poderosa que o crime (REVISTA Galileu, junho 2010). 
Para Tucherman, Oiticica e Cavalcanti (2010b), a promessa de futuro é característica das matérias jornalísticas sobre ciência, as quais se utilizam da apresentação de promessas para obter visibilidade e financiamento para as pesquisas científicas divulgadas. As pesquisadoras afirmam que, apesar das falhas e limitações da atividade científica, a crença na ciência e nas suas determinações para o futuro ainda fazem parte dos pensamentos do senso comum e até dos mais sofisticados teóricos. A promessa em novas descobertas científicas pode ser observada nos exemplos 8 e 9 do corpus analisado:

Exemplo 8: Mas as recentes teorias sobre depressão trazem uma inovação preciosa ao nos mostrar que a tristeza e o pessimismo podem não ser de todo ruim, ajudando-nos a compreender nossas reações humanas de uma maneira mais natural (REVISTA Galileu, maio 2010).

Exemplo 9: A possibilidade de criar um alívio para esse mal vem movendo cientistas do mundo todo (REVISTA Galileu, julho 2010).

Além de trazer elementos da matriz moderna da ciência, os elementos ipse também jogam com conceitos pós-modernos da atividade, fazendo com que sua identidade não seja identificável com os elementos do seu passado. Assim, aparece o diferente, que move a identidade da sua fixidez moderna. Nessa perspectiva, podemos entender que há o surgimento de alguns elementos que entendem a atividade científica como de natureza interdisciplinar e de não ser a única resposta para os anseios humanos, uma ciência nomeada por Santos (1989) como pós-moderna.

Assim, os elementos de ipseidade podem ser relacionados com a formação discursiva da pós-modernidade, a qual se refere à ciência como apenas uma de tantas soluções para os problemas sociais. Essa posição de enunciação se constituiu com a crise do projeto de modernidade, no início do século $\mathrm{XX}$, em que os ideais iluministas de caráter racional, otimista e de progresso confiado à racionalidade são invalidados. $\mathrm{Na}$ pós-modernidade, a ciência começou a ser vista não mais como a grande narrativa que daria soluções para o ser humano, mas sim como uma das respostas entre inúmeras outras possíveis. Os exemplos 10, 11 e 12 trazem essa configuração: 
Exemplo 10: Apesar de ser um entusiasta da comida futurista, Hervé This sabe que esse não é o único caminho. A comida com bolinhas é apenas uma das três vias para a alimentação do futuro (REVISTA Galileu, abr. 2010).

Exemplo 11: Algumas respostas para esse paradoxo podem vir da ciência, da história e dessa coisa de comer com responsabilidade (REVISTA Galileu, abr. 2010).

Exemplo 12: O que a ciência e você vão fazer para salvar da fome e da obesidade um planeta com 10 bilhões de pessoas? (REVISTA Galileu, abr. 2010).

A concepção pós-moderna da ciência também se refere à atividade como um discurso que não revela a realidade, mas sim que se constrói por meio de proposições ditas objetivas (CORACINI, 1991). Assim, encontramos os exemplos 13 e 14 que fazem com que a ciência seja entendida como processo, o que, consequentemente, faz com que a identidade fixa dela seja modificada.

Exemplo 13: Mas só recentemente passou-se a aventar que a doença tenha aspectos positivos.(REVISTA Galileu, maio 2010). (grifo nosso).

Exemplo 14: Uma ala da psicologia evolucionista passon recentemente a ver a questão sob um prisma bem diferente (REVISTA Galileu, maio 2010). (grifo nosso)

A abordagem da ciência como construção a apresenta como um saber que não possui verdades absolutas, mas está sempre na busca por soluções. O ponto de vista pós-moderno relativiza a confiança na ciência, pois entende que, como toda atividade humana, ela também é construída por meio de escolhas e está sujeita a erros e falhas. Isso pode ser notado nos exemplos 15, 16 e 17:

Exemplo 15: O experimento chega bem perto do que seria uma real pílula para apagar más-lembranças. Mas também oferece grandes riscos (REVISTA Galileu, julho 2010). (grifo nosso). 
Exemplo 16: Por enquanto, a eficácia só pode ser comprovada em ratinhos (REVISTA Galileu, julho 2010).

Exemplo 17: E comer como cidadão significa equilibrar a fome com a vontade de comer num planeta bem de saúde. O futuro do seu almoço não é aguardar que a ciência descubra uma pílula de picanha e um comprimido de arroz (REVISTA Galileu, abr. 2010).

A tensão entre elementos ipse e idem faz com que a identidade construída pela revista Galileu seja uma identidade fragmentada, característica do sujeito pós-moderno descrito por Hall (2005). Assim, para se firmarem em um produto cultural, as identidades sobre ciência utilizam elementos de formações discursivas distintas, como a da modernidade (da ciência moderna) e da pós-modernidade (ciência pósmoderna).

\section{CONSIDERAÇÕES FINAIS}

Este artigo pretendeu entender como se produz a identidade de ciência na revista Galileu e, para tanto, utilizou os conceitos de mesmidade e ipseidade da teoria narrativa de Ricoeur (1991). Por meio da análise, pode-se verificar que a constituição da identidade de ciência na revista é fragmentada e se constrói numa heterogeneidade de fragmentos de identidades ofertados pelos percursos históricos que a constituíram.

Assim, a questão da identidade, na pós-modernidade, se define justamente por essa fragmentação e multiplicidade, que, na revista, aparece representada pela justaposição entre elementos das formações discursivas da modernidade e da pós-modernidade. Constituídas num jogo entre a dialética idem $x$ ipse, as identidades de ciência da revista possuem elementos relacionados ao novo, ao futuro e à mudança (característica da ciência pós-moderna), mas, ainda trazem elementos idem, os quais remetem a atividade ao seu passado, à sua memória e fixidez modernas.

Os elementos idem pretendem trazer segurança para o leitor da revista ao se referirem à ciência como legítima ao oferecer explicações 
racionais aceitas universalmente e, por isso, se relaciona à formação discursiva da modernidade, que vincula a atividade científica ao cientificismo e ao progresso. No entanto, esses elementos estão em permanente tensão com a promessa oferecida ao leitor, por meio da identidade ipse.

Os elementos ipse se relacionam ao futuro e à promessa, que coloca a ciência em posição de oferecer soluções para os problemas humanos. Assim, eles se vinculam à formação discursiva da modernidade, que tem a ciência como atividade inovadora e desenvolvimentista. No entanto, os elementos ipse também jogam com a diferença, afastando-se da identidade fixa da ciência e, assim, construindo-a como uma identidade aberta, relacionada à formação discursiva da pós-modernidade e ao conceito de ciência pós-moderna. Nesse processo, a atividade não é mais responsável em fornecer a resposta a todos os anseios humanos, como pensavam os modernos, e sim é vista como um conhecimento em processo que pode ser transdisciplinar.

Apesar de os elementos ipse, que produzem uma identidade pósmoderna para a ciência, serem discretos no objeto analisado, é fundamental entender essa relação que existe entre os elementos idem e ipse na constituição da identidade da ciência. Ao analisar esse movimento, compreende-se que as identidades não são construídas fixamente, mas sim podem ser modificadas neste processo entre memória e promessa.

\section{REFERÊNCIAS}

BAUMAN, Z. From pilgrim to tourist - or a short history of identity. In: HALL, S. e GAY, P. (Orgs.) Questions of cultural identity. Londres: Sage Publications, 1996.

CORACINI, M. J. R.Um fazer persuasivo: o discurso subjetivo da ciência. São Paulo: EDUSC, 1991.

- As representações do saber científico na constituição da identidade do sujeito-professor e do discurso de sala de aula. In: CORACINI, M. J. R. (Org.) Identidade e discurso. Campinas, SP: EdUnicamp, 2003. 
FLORIANI, D. Diálogos interdisciplinares para uma agenda socioambiental: breve inventário do debate sobre ciência, sociedade e natureza. Revista Desenvolvimento e Meio Ambiente, n.1, p.21-39, jan/jun. 2000.

FOUCAULT, M. A arqueologia do saber. São Paulo: Vozes, 1972.

GIDDENS, A. As conseqüências da modernidade. São Paulo: EdUnesp, 1991.

Modernidade e identidade. Rio de Janeiro: Jorge Zahar, 2002.

GREIMAS, A.J.; COURTÉS, J. Dicionário de semiótica. São Paulo: Contexto, 2008.

GOMES, I.; HOLZBACH, A.; TAVEIRA, M. Mídia impressa e construção da identidade de ciência. In: SILVEIRA, A. C. M. (Org.). Divulgação científica e TICs. Santa Maria: FACOS-UFSM, 2003. 256p. p.216-237

HALL, S. Quem precisa de identidade? In: SILVA, T. (Org.) Identidade e diferença: a perspectiva dos estudos culturais. Rio de Janeiro: Vozes, 2009.

2005.

A identidade cultural na pós-modernidade. Rio de Janeiro: DP\&A,

JAPIASSÚ, H. Nem tudo é relative: a questão da verdade. São Paulo: Editora Letras \& Letras, 2000.

. Nascimento e morte das ciências humanas. Rio de Janeiro: Francisco Alves, 1982.

O mito da neutralidade científica. Rio de Janeiro: Imago, 1975.

KELLNER, D. A cultura da mídia. Bauru, SP: EDUSC, 2001.

LYOTARD, J.-F. O pós-moderno. 3. ed. Rio de Janeiro: José Olympio, 1988.

MIRA, M. O leitor e a banca de revistas: a segmentação da cultura no século XX. São Paulo: Olho d’Água/ Fapesp, 2001.

ORLANDI, E. Identidade lingüística escolar. In: SIGNORINI, I. (Org.)

Língua(gem) e identidade. Campinas: Mercado de Letras/FAPESP, 1998.

PIPPI, J. Ciência, tecnologia e inovação: interdiscursividade jornalística, reformulação discursiva e heterogeneidades. 2005. 98f. Dissertação (Mestrado em Extensão Rural) - Programa de Pós-graduação em Extensão Rural, Universidade Federal de Santa Maria, Santa Maria, 2005.

RICOEUR, P. O si-mesmo como um outro. Campinas, SP: 1991. 
SANTOS, B. S. Um discurso sobre as ciências. São Paulo: Cortez, 2006. 1989. . Introdução a uma ciência pós-moderna. Rio de Janeiro: Graal,

SILVA, T. A produção social da identidade e da diferença. In: SILVA, T. (Org.) Identidade e diferença: a perspectiva dos estudos culturais. Rio de Janeiro: Vozes, 2009.

SILVA, D.; OITICICA, L. Revistas científicas e ciências da vida: Longevidade, medicalização e alimentação no contexto do biopoder. CONGRESSO DE CIÊNCIAS DA COMUNICAÇÃO NA REGIÃO SUDESTE, 14.,2009. Anais... Rio de Janeiro, 2009.

SILVEIRA, A. Mídia e discursividade. O concerto polifônico das fronteiras brasileiras. CONGRESSO BRASILEIRO DE CIÊNCIAS DA COMUNICAÇÃO, 30., 2007. Anais... Santos (SP), 2007.

SODRÉ, M. Antropológica do espelho: uma teoria da comunicação linear e em rede. Rio de Janeiro: Vozes, 2002.

TUCHERMAN, I.; OITICICA, L.; CAVALCANTI, C. Revistas de divulgação científica e ciências da vida: encontros e desencontros. Intercom - Revista Brasileira de Ciências da Comunicação, São Paulo, v. 33, n. 1, p. 277-295, jan./jun. 2010a.

. Revistas científicas, mediações e retóricas: Encontros e desencontros

entre a mídia e o biopoder. In: BRAGA, J.; LOPES, M.; MARTINO, L. (Orgs.) Pesquisa Empírica em Comunicação. Livro Compós 2010. São Paulo: Coedição Paulus/Compós, 2010b.

\section{PERIÓDICOS}

A nova tropa de elite. Revista Galileu, São Paulo, n. 227, p. 44-55, jun.2010.

O futuro da comida. Revista Galileu, São Paulo, n. 225, p. 46-51, abr. 2010.

O lado bom da depressão. Revista Galileu, São Paulo, n. 226, p. 42-49, maio 2010.

Uma cura para todos os medos? Revista Galileu, São Paulo, n. 228, p. 34-42, jul.2010. 
Recebido em: 18/04/11. Aprovado em: 28/07/11.

Title: Between memory and promise: the identity of science in Galileu magazine

Authors: Natália Flores; Ada Cristina Machado da Silveira

Abstract: In this paper, it is examined how the identity of science is produced in Galileu magazine. The analysis assumes that the media is constitutive of identities, which not only relate to a particular product, but are built by the confluence of different elements according to the historicity of their discursive formations. Our guiding questions ask about the presence of ipse and idem elements - of the narrative identity in Ricoeur (1991) - and its relation with discursive formations in the discursive formation of the identity of science in the discourse of the magazine. The corpus of the research includes four cover stories of Galileu magazine, namely, the editions of April, May, June and July 2010. It analyzes how the activity of science, from a modern or a postmodern perspective, allows for the construction of science identities in Galileu and how it builds the tension between sameness and ipseness, between memory and promise.

Keywords: Identity. Discursive formations. Galileu magazine.

Titulo: Entre memoria y promesa: la identidad de ciencia en la revista Galileu Autores: Natália Flores; Ada Cristina Machado da Silveira

Resumen: En este articulo, se pretendió analizar como se produce la identidad de ciencia en la revista Galileu. Partimos del supuesto de que los medios son constitutivos de las identidades, las cuales no se refieren apenas a un producto determinado, sino que se construyen en la confluencia de diferentes elementos de acuerdo con la historicidad de sus formaciones discursivas. Nuestras cuestiones orientadoras indagan sobre la presencia de elementos idem e ipse - de la identidad narrativa en Paul Ricoeur (1991) -, y su relación con las formaciones discursivas en la constitución de la identidad de ciencia en el discurso de la revista. El corpus de la investigación se constituye de cuatro reportajes de tapa de la revista Galileu, de las ediciones de abril, mayo, junio y julio de 2010. Se analiza como la actividad de la ciencia en una concepción moderna o posmoderna colabora para la construcción de las identidades de ciencia en la Galileu y constituye la tensión entre igualdad e individualidad, entre memoria y promesa.

Palabras clave: Identidad. Formaciones discursivas. Revista Galileu.

FLORES; SILVEIRA - Entre memória e promessa... 